\title{
Analysis Different Types of Coating Removal Techniques in Aerospace Industries: Comparative Study
}

\author{
Afshin Davarpanah ${ }^{1}$, Afshin Hosseini Hemat ${ }^{2}$, Mojtaba Zarei ${ }^{3}$ \\ ${ }^{1,2}$ Young Elite Sponsors Institute, Tehran, Iran \\ ${ }^{3}$ Department of chemistry Engineering, Shahreza Branch, Islamic Azad University, Shahreza, Iran
}

\begin{abstract}
In the recent years, aviation industry in terms of corrosion have been undertook with million pounds. Therefore, by appropriate maintenance and husbandry, these effects could be decreased. Most of the aircrafts could be maintained by long term and short term inspection check. Nowadays, one of the chief aims of using Coating removal methodologies in controlling the amount of corrosion in aviation industry. It includes High pressurized water, Sponging media, plastic media extracted from crude oil and bio engineering basic media. If the Coatings removal techniques have not operate appropriately, it could erode metal subsurface. In this research, different types of coating removal methods in the aviation industry are being illustrated and compared together. Engineering bio-based media has more advantages than the other and it can be used between 8-15 times. All in all, due to selecting the greatest appeal of proper method would be considered the safety and issue of operator's health as the most common criteria.
\end{abstract}

Keywords: coating removal, aviation industry, engineering bio-based media

\section{INTRODUCTION}

\subsection{Corrosion}

Material and sorroundeed environmental situation could cause by these two effects that often occurred simultaneously:

$>$ Chemical (oxidation)

$>$ Electrochemical (galvanic)

In both cases, metal was altered to the metal compound such as carbonates, hydroxides, oxides and sulphates. Corrosion stages are being contributed with two simultaneous changes. Metals are inveighed against the anodic changes, until it take under a cathodic change $[1,2]$.

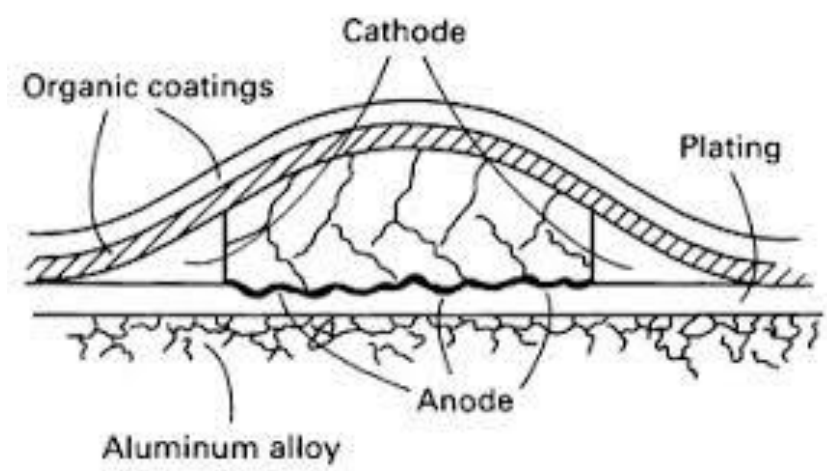

Figure1. Corrosion process

\subsubsection{Types of corrosion that mostly seen on the aviation industry}

There are several types of corrosion. This types are mostly depended on the surrounded metals among the susceptible environment, their applications, weather situation and current corrosion factor. Several types of corrosion that are being seen in the aircraft structures are listed below [3, 4].

$>$ Surface corrosion 


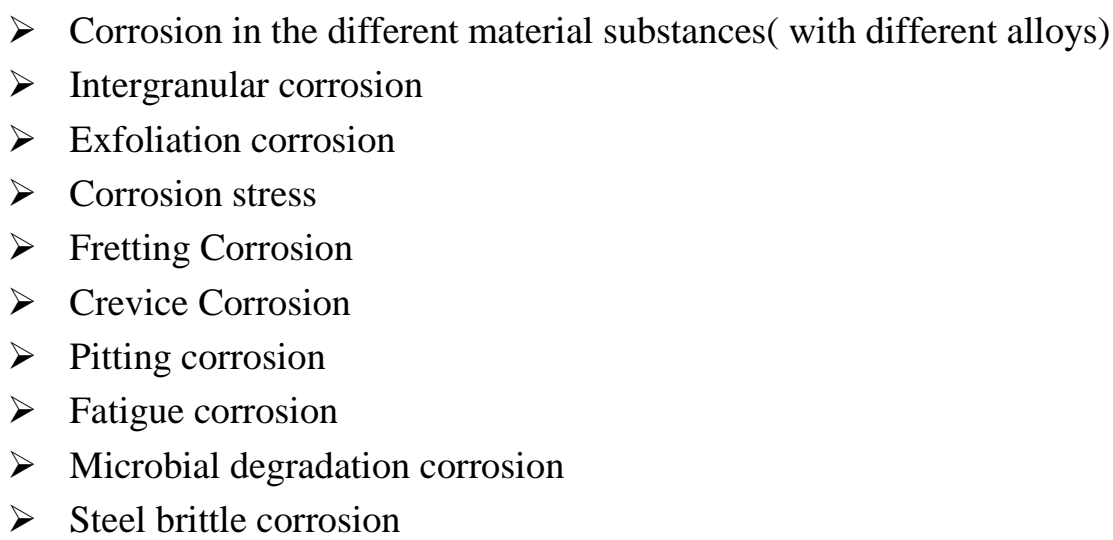

\subsubsection{Factors affecting on corrosion.}

Several factors effect on the reason, type, corrosion speed and metal extremity corrosion. Even though, some of them are out range of aircraft designers and maintenance engineer, some of them are being controlled. These factors are mentioned below:[5,6]

$>$ Type and size of the metal

$>$ Environmental situations:

$\checkmark$ Marine environmental (take in the salty water) increase the corrosion rate.

$\checkmark$ Humidity

$\checkmark$ High temperature

$>$ Corrosive factors

$\checkmark$ Dust and soil in the atmosphere

$\checkmark$ Oil residuals in the engines

$\checkmark$ Remain welding particles

1.1.3. General methods for removing corrosion.

$>$ Inspect the defections

$>$ Neutralize the residual remains

$>$ Remove each part of corrosion that would be convenient

$>$ Clean the corrosion area from dusts

$>$ Using temporary or constant coatings after painting completely

\subsection{Coating}

Nowadays, numerous kinds of coatings are being found in the aircraft industries. Take, Aircraft frameworks and large structures have plastic coating for example that is located on the metal surface which was followed by a largely cross sectional linking polyurethane on the top section [7]. Coatings are substantially made up four components: resin, pigment, fillers and solvents. Resin would act such a matrix for pigment and fillers. Regarding chemistry properties, several specifications could be proportionated as a coating removal techniques requirements $[8,9]$.

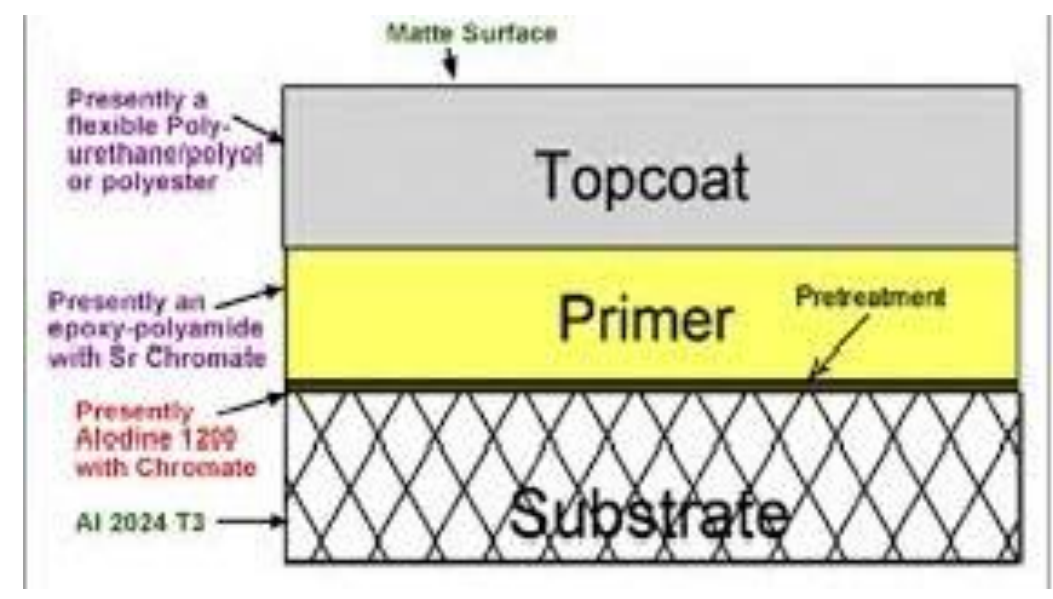

Figure2. Coating process 


\section{METHODOLOGY OF WORK}

\subsection{Coating removal methods}

The vast majority of modern coating removal methods are used these below mechanisms generally:

$>$ Disassociation of molecule

$>$ Methodologies using thermal specification

$>$ Impact coating methods

Disassociation of molecule section due to formation and structure of the strippers which contain all chemical strippers, are being divided to three different categories as below:

$>$ Acidized strippers with $\mathrm{PH}$ below 7

Neutral strippers $(\mathrm{PH}=7)$

$>$ Alkaline strippers with $\mathrm{PH}$ more than 7

\subsection{Types of impact coating}

$>$ High pressurized water

$>$ Sponging media

$>$ plastic media extracted from crude oil

$>$ bio engineering basic media

\subsubsection{High pressurized water}

High pressurized water is basically operated by very specific nozzles within the pressure of 2000 bar up to 4000 bar for the first time in the year 1990. Experimental investigation demonstrated that in these pressures only surficial coatings could be eliminated. By utilizing this methodology as a repeated activity by applying on the aircraft body which include thin layers of aluminum skins especially $0.4 \mathrm{~mm}$ thickness, the effects on the mechanical properties of metal would be decreaed dramatically. The success of this process are mostly appear on the smaller size units among a close system of water cycling.

\section{Advantages:}

> By applying appropriate observation, high pressurized water method could be act as a proper methods in removing the coatings from the strict structures with the minimum effect.

$>$ Selective stripping is sometimes feasible

\section{Disadvantages:}

$>$ Costs of Equipment,qualified operators and necessary engineering requirements are being observed to be moderate to high expenses.

$>$ This method have not been used in composite structures due to performing bad impacts.

$>$ Water must be created to remove coating debris.

\subsubsection{Sponging media}

Sponging media first in the middle of 1990s had been improved and industrialized by compressing the dry air against the surficial section. The type of media is a mixture of a soft foam or fibred carrier, which performs as a matrix, and several kinds of abrasive grits (such as plastic, mineral, etc.) which they are embedded in the matrix.

\section{Advantages:}

$>$ This type of Media could be applied between 6-12 times.

$>$ There is no chemical processes which is safe for humans.

$>$ Selective stripping is sometimes feasible.

\section{Disadvantages:}

$>$ The types of dust which is produced in this method like chromium may contain heavy toxin metals during the procedure of coating removals.

$>$ It needs appropriate protection 


\subsubsection{Plastic media extracted from crude oil}

Plastic media extracted from crude oil was first used in the year 1940 by using types of plastic which was extracted from crude by DuPont Company. The impacts of these method were not understand until in the year 1980 which was found that DCM-based chemical strippers started to emerge in the early 1980s.

\section{Advantages}

$>$ Due to types of media, it could be used between 2-3 times.

$>$ There is no chemical processes which is safe for humans.

\section{Disadvantages}

$>$ One types of media which is called Aggressive type could have detrimental effects on the metallic and compositional sections.

\subsubsection{Bio engineering basic media}

Bio engineering basic media types was firstly appeared in the year 1991 in the aviation industry. On that time, most of the manufacturers realized that special types of bio engineering basic media which is called soft media with amount of Moh,s hardness(relatively 2.0) and specific gravity of $1.45 \mathrm{~g} / \mathrm{cm} 3$, had specific emphasis on the aviation industry on that time.

\section{Advantages}

$>$ Regarding to the types of media and other effective parameters, these coatings could be reused between to Depending on media type and parameters 5 to 15 times.

$>$ There is no chemical processes which is safe for humans.

\section{Disadvantages}

$>$ The types of dust which is produced in this method may contain heavy toxin metals during the procedure of coating removals.

$>$ It needs appropriate protection.

\section{CONCLUSIONS}

Because we have several equipments and factors involved, it doesn't have asimple solution for removing coatings in an aerospace industries. In terms of advantages and disadvantages of any coating in several situations, it must be economically choose a method for removing coatings in aircraft industries. Consequently, labor safety and the economic will be the two critical priority when selecting the coatings techniques.

\section{REFERENCES}

[1] Fontana M.G, Corrosion Engineering $3^{\text {rd }}$ Edition. McGraw Hill, ISBN 0-07-021463-8, 1986,556 pp.

[2] NASA (National Aeronautics and Space Administration), joint EPA/NASA/USAF interagency DE painting study. Report Number. NP-1999-12-152-MSFC, 1999, 100pp.

[3] GRIMES J., Process strips paint off B-1 s, USAF press release, 7/18/2003

[4] GATES J., New 787 gos on diet to keep that svelte look airlines love, Seattle Times. 11/21/2005

[5] PAULIR. Alternative processes to methylene chloride chemical strippers, a review of progress to date, 1995 Aerospace/Airline plating and metal finishing forum. American Electroplaters and surface Finishers Society

[6] MONETTED. OESTRIECHJ, Enhanced type VII plastic media e-strip (MIL-P-85891a) for military aerospace applications, DoD Industry Advanced Coating Removal Conference, 2002, 11 pp.

[7] LARSON B., A study of the factors affecting the sensitivity of liquid penetrant inspections: a review of literature from 1970-1998, FAA Technical Report, DOT/FAA/AR 01-95, 2002, 51 pp.

[8] HART W.G.J., Paint stripping techniques for composite aircraft components, National Aerospace Laboratory Technical Publication, NLR-TP-2003-357, 2003, 13 pp.

[9] Meguid S.A., Effect of partial-coverage upon the fatigue fracture behavior of peened components,Fatigue Fracture Engineering Material Structures, Vol 14 No 15, Fatigue of Engineering materialsLtd. 8756-758X, 1991, pp 515-530 


\section{AUTHORS' BIOGRAPHY}

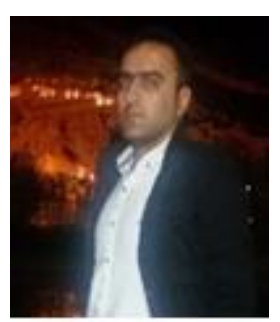

Afshin Davarpanah, Master degree of Petroleum Engineering at Islamic Azad University, Tehran science and research Branch. My current interests in petroleum engineering sciences include a full-field study of Data Gathering, Reservoir Simulation, History Matching and Prediction. Data gathering stage mainly consisted of Well Logging, Coring, Seismic Survey, Geological Survey and DST (or other well tests). History Matching is an extremely crucial stage in full field study in order to get a more reliable prediction of the reservoir behavior. There are always some data which do not match with the true condition of the reservoir.

What I did at this stage as a petroleum engineer was to simulate and find the unmatched data and resolve the discrepancies.

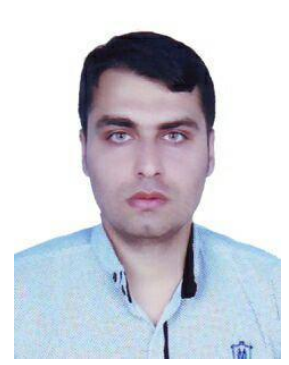

Afshin Hosseini Hemat, Master degree of Petroleum Engineering at Imam Khomeini International University. At the moment, I am working for Kaveh Methanol Petrochemical as a Process Engineer from April 2015 till now. My current interests in petroleum engineering sciences include a full-field study of Data Gathering, Reservoir Simulation, History Matching and Prediction. Data gathering stage mainly consisted of Well Logging, Coring, Seismic Survey, Geological Survey and DST (or other well tests).

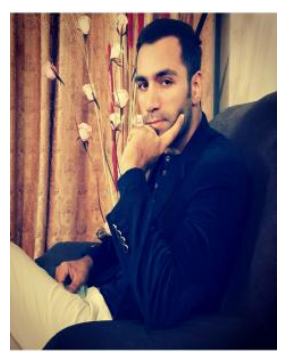

Mojtaba Zarei, Master degree of Chemistry Engineering at Islamic Azad University, Shahreza Branch. My current interests in Chemistry engineering sciences include a full-field study of Data Gathering, Process Simulation, and Enhanced Oil Recovery Methods. As a Chemistry Engineer, I systematically used my knowledge and experience to analyze the situation and then define, design and implement a method to reduce the environmental effects by reducing the unnecessary burning of gases at the flares. 